\title{
Efficacy and Safety of Cytoreductive Therapies in Patients with Essential Thrombocythaemia Aged >80 Years: An Interim Analysis of the EXELS Study
}

\author{
Jean-Jacques Kiladjian - Carlos Besses - Martin Griesshammer • \\ Luigi Gugliotta - Claire Harrison - Ruth Coll · Jonathan Smith • \\ Gunnar Birgegård
}

Published online: 27 November 2012

(c) The Author(s) 2012. This article is published with open access at Springerlink.com

\begin{abstract}
Background The median age of patients diagnosed with essential thrombocythaemia (ET) is $65-70$ years but the management of very elderly patients (aged $>80$ years) with ET has not been well characterized.

Objective This study aimed to document the treatment patterns of very elderly patients with ET in a multinational, real-world setting.

Study Design EXELS (Evaluation of Xagrid Efficacy and Long-term Safety) is a phase IV observational study, designed to monitor the efficacy and safety of cytoreductive therapies in clinical practice. In total, 3,598 high-risk patients with ET were recruited from May 2005 to April 2009, in 13 European countries. Data were collected at registration and every 6 months thereafter for 5 years. This
\end{abstract}

J.-J. Kiladjian $(\bowtie)$

AP-HP, Hôpital Saint-Louis, Centre d'Investigations Cliniques,

Paris, France

e-mail: jean-jacques.kiladjian@sls.aphp.fr

C. Besses

Hospital del Mar-IMIM, Barcelona, Spain

\section{Griesshammer}

Johannes Wesling Klinikum Minden, Minden, Germany

L. Gugliotta

Department of Hematology "L. \& A. Seragnoli",

St Orsola-Malpighi Hospital, Bologna, Italy

C. Harrison

Guy's and St Thomas' NHS Foundation Trust, London, UK

R. Coll · J. Smith

Shire Pharmaceuticals Ltd, Basingstoke, UK

G. Birgegård

Uppsala University, Uppsala, Sweden analysis was performed on a data-cut taken approximately 2 years after the last patient was registered.

Patients In total, 395 patients aged $>80$ years at registration into EXELS were included in the analysis; of these, $42.2 \%$ had experienced a previous thrombohaemorrhagic event.

Results At registration, the most frequently prescribed cytoreductive therapy for patients aged $>80$ years was hydroxycarbamide (HC), which accounted for $82.8 \%$ of patients whereas anagrelide use was less frequent $(8.6 \%)$. Very elderly patients were more likely to be switched from anagrelide than from HC (47.1 vs. $17.4 \%$; $95 \%$ confidence interval for difference in proportion 12.4-46.9; Chisquared test $p<0.001)$. Median platelet count during treatment was $\sim 430 \times 10^{9} / \mathrm{L}$. In patients aged $>80$ years, the main reason for switch was intolerance/side effects (34.1\%); 0/16 patients reported treatment with anagrelide was non-efficacious compared with 8/57 (14\%) patients receiving $\mathrm{HC}$, and 7/16 (43.8\%) anagrelide patients switched because of intolerance versus 18/57 (31.6\%) patients receiving $\mathrm{HC}$. At least one predefined clinical event (PDE) was experienced by $27.3 \%$ of patients aged $>80$ years. The most common PDEs reported in the very elderly age group were death (non-PDE related; $11.1 \%$ ), other cardiovascular symptoms $(5.8 \%)$, haematological transformation (3.8\%), congestive heart failure $(3.3 \%)$, myocardial infarction and angina $(2.8 \%)$, and thromboembolic events $(6.3 \%)$.

Conclusion Well-tolerated and effective cytoreductive therapy has been achieved in patients aged $>80$ years by following individual treatment modalities that appear in agreement with the recent European LeukemiaNet (ELN) guidelines.

Clinical Trial Registration Registered as ClinicalTrials.gov identifier NCT00567502; Protocol No: SPD422-401. 


\section{Introduction}

Essential thrombocythaemia (ET) is a chronic myeloproliferative neoplasm (MPN) characterized by the overproduction of platelets by megakaryocytes [1]. The median age at diagnosis of ET is approximately 65-70 years with its incidence increasing with age $[2,3]$. Previous retrospective studies suggest that patients with ET aged $>60$ years have an increased risk of thrombotic events [4, 5]. However, previous randomized controlled trials suggest that thrombosis risk is reduced when patients are treated with cytoreductive therapy [6, 7]. Thus, according to international guidelines, high-risk patients with ET (patients $>60$ years of age; history of thrombohaemorrhagic events; initial platelet count $>1500 \times 10^{9} / \mathrm{L}$ ) should be considered for cytoreductive therapy [8].

Hydroxycarbamide (HC) is currently recommended for first-line therapy in high-risk patients with ET of all ages, although it should be used with caution in patients aged $<40$ years [8]. Anagrelide is approved for second-line treatment of ET in Europe [9]. Both HC and anagrelide have been used in patients with a wide range of ages $[6$, 10-17]. Since the overall population with ET are of advanced age, we believe it would be of value to more closely assess the very elderly patients (aged $>80$ years), for whom different treatment decisions may be appropriate. Elderly patients are known to have greater thrombotic risk than younger patients in the general population [18] and this risk is already increased in patients with ET. To date, there has been limited information reported regarding treatment practice in very elderly patients with ET [19].

EXELS (Evaluation of Xagrid Efficacy and Long-term Safety) is a phase IV study, designed to monitor the safety of anagrelide and other cytoreductive therapies in patients with ET in routine clinical practice. Additional objectives include improving the understanding of the risks involved in long-term use of cytoreductive agents in ET. The aim of this analysis is to characterize the baseline features and management of patients with ET aged $>80$ years, who were enrolled in the EXELS study.

\section{Design and Methods}

\subsection{Trial Design}

This is an ongoing phase IV non-interventional postapproval commitment study observing high-risk patients with ET who are treated with cytoreductive therapy. The EXELS study (ClinicalTrials.gov identifier NCT00567502; Protocol: SPD422-401) is being conducted in 13 European countries: Denmark, Finland, France, Germany, Greece,
Ireland, Italy, The Netherlands, Norway, Portugal, Spain, Sweden and the United Kingdom. The first patient entered the study in May 2005 following local ethics committee approval at all participating centres. Predefined clinical events and biological data (including full blood counts) were collected from each patient at the time of registration and every 6 months thereafter for 5 years, using an electronic data capture system. The last patient was registered in April 2009 and the study will be completed in June 2014. This analysis was performed on a data-cut taken in March 2011. The EXELS study is non-interventional and no comparisons are made between groups due to the noninterventional nature of the study.

\subsection{Participants}

Patients with a diagnosis of ET according to the World Health Organization [1] and/or Polycythemia Vera Study Group criteria [20] with one or more high-risk features (patients $>60$ years of age; history of thrombohaemorrhagic events; initial platelet count $>1000 \times 10^{9} / \mathrm{L}$ ), and receiving cytoreductive therapy, were eligible for study inclusion. Exclusion criteria were limited to the contraindications listed in the product information of the cytoreductive therapy. Written informed consent was obtained from all patients before entering the study.

\subsection{Treatment}

As this was a non-interventional study, the choice of cytoreductive therapy was determined prior to study registration and patients were managed according to local practice at the discretion of the investigators. Data related to predefined events (PDEs), suspected serious adverse reactions (SSARs), platelet count and any changes to medication were recorded at each 6-month update. Patients with multiple events of the same PDE category were only counted once for each treatment received. Thromboembolic events were defined in this analysis as the following PDEs: myocardial infarction (MI) and angina, stroke, transient ischaemic attack (TIA), intermittent claudication/ digital ischaemia, and venous thromboembolic events. All safety evaluations and procedures were performed in accordance with routine clinical practice.

\subsection{Statistical Methods}

Ninety-five percent confidence intervals (CIs) for proportions were calculated and assessed for statistical significance using Chi-squared tests between reasons for treatment switch. A repeated measures analysis of variance (ANOVA) was used to determine whether the inclusion of treatment-naïve patients had affected the differences in 
platelet counts over time. The statistical software used was SAS version 9.2 (SAS Institute, Cary, NC, USA).

\section{Results}

\subsection{Patients}

A total of 3,598 patients were enrolled in the EXELS study, including $395(11 \%)$ very elderly (aged >80 years) patients. Patient demographics and characteristics at study registration are shown in Table 1 . More than two-thirds $(68.6 \%)$ of the very elderly patients were female. As would be expected, a notable proportion of patients aged $>80$ years had experienced a previous vascular or haemorrhagic event $(42.2 \%)$. Sixty-three of these patients $(16 \%)$ were treatment-naïve (defined as those who had only recently started cytoreductive treatment of any kind, within 6 months prior to registration).

\subsection{Treatment}

The treatments patients aged $>80$ years were receiving at enrolment are presented in Fig. 1. HC and anagrelide represent the two main cytoreductive treatments used as monotherapy in $91.4 \%$ of the very elderly patients in EXELS. In the defined group, $\mathrm{HC}$ was most frequently prescribed $(82.8 \%)$ and anagrelide use was much less frequent $(8.6 \%)$. At enrolment into the EXELS study, $80.5 \%(318 / 395)$ of the very elderly patients were receiving their first cytoreductive treatment but only $3.46 \%(11 / 395)$ were receiving anagrelide. In total, $69.4 \%$ of the very elderly patients were receiving antiaggregatory therapy.

\subsection{Blood Cell Counts}

\subsubsection{Platelet Count}

Platelet counts showed an initial reduction in all age groups from registration to 6 months, which was found to be significantly driven by the start of cytoreductive therapy in treatment-naïve patients (ANOVA; $p<0.001$ ). Following the initial reduction, platelet counts remained fairly consistent at a median count of $\sim 430 \times 10^{9} / \mathrm{L}$ in the very elderly patients (Fig. 2a).

\subsubsection{Haemoglobin}

The median haemoglobin $(\mathrm{Hb})$ values remained relatively stable in the range of 11.5-12.29 g/dL throughout the study in patients aged $>80$ years (Fig. $2 b$ ).

\subsubsection{Haematocrit}

A slight variation over time (within 0.36-0.40) in median haematocrit counts was observed in patients aged $>80$ years (Fig. $2 c$ ).

\subsubsection{White Blood Cells}

A slight variation in the median white blood cell count (between 5.6 and $7.1 \times 10^{9} / \mathrm{L}$ ) was observed in the very elderly patients over time (Fig. 2d).

It is important to note that the EXELS study is ongoing; therefore, for the entire clinical laboratory data reported at this data-cut, the $n$-numbers declined over time, as some patients had not completed the full 60-month observation period at the time of the data cut.
Table 1 Summary of demographic and patient characteristics at study enrolment in patients aged $>80$ years and the total EXELS population

Patients with missing data: ${ }^{\mathrm{a}} n=2 ;{ }^{\mathrm{b}} n=15 ;{ }^{\mathrm{c}} n=29$ $\mathrm{CI}$ confidence interval, $\mathrm{Hb}$ haemoglobin, Hct haematocrit, $W B C$ white blood cells

\begin{tabular}{|c|c|c|}
\hline \multirow[t]{2}{*}{ Characteristic } & \multicolumn{2}{|l|}{ Age category } \\
\hline & Age $>80$ years & Total \\
\hline Total, $^{\mathrm{a}} \mathrm{n}(\%)$ & $395(11.0)$ & 3,598 \\
\hline Female, ${ }^{b}$ n $(\%)[95 \% \mathrm{CI}]$ & 271 (68.6) [66.7-70.5] & $2,194(61.0)$ \\
\hline Male, $^{\mathrm{b}} \mathrm{n}(\%)[95 \% \mathrm{CI}]$ & $124(31.4)[26.8-36.2]$ & $1,389(38.6)$ \\
\hline \multicolumn{3}{|l|}{ Haematological values, mean (SD) } \\
\hline $\mathrm{Hb}(\mathrm{g} / \mathrm{dL})$ & $11.96(1.69)$ & $12.87(1.635)$ \\
\hline Hct & $0.37(0.05)$ & $0.39(0.045)$ \\
\hline WBC $\left(\times 10^{9} / \mathrm{L}\right)$ & $7.44(4.57)$ & $7.32(4.075)$ \\
\hline Platelets $\left(\times 10^{9} / \mathrm{L}\right)$ & $485.71(197.99)$ & $491.85(227.84)$ \\
\hline Treatment-naïve, ${ }^{\mathrm{a}} \mathrm{n}(\%)[95 \% \mathrm{CI}]$ & $63(16.0)[12.5-19.9]$ & $694(19.3)$ \\
\hline $\begin{array}{l}\text { Anti-aggregatory therapy at } \\
\text { registration, }{ }^{a} \mathrm{n}(\%)[95 \% \mathrm{CI}]\end{array}$ & $274(69.4)[64.6-73.9]$ & $2,505(69.6)$ \\
\hline $\begin{array}{l}\text { Haemorrhagic and vascular } \\
\text { events prior to registration, }{ }^{\mathrm{c}} \mathrm{n}(\%) \\
{[95 \% \mathrm{CI}]}\end{array}$ & $166(42.2)[37.3-47.3]$ & $1,344(37.4)$ \\
\hline
\end{tabular}




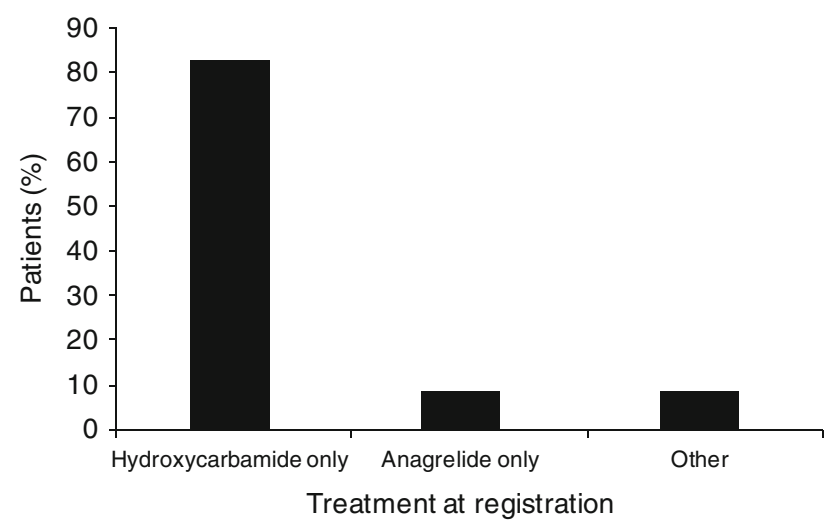

Fig. 1 Treatment at registration in patients aged $>80$ years. 'Other' includes interferon, busulphan, pipobroman, P32, and anagrelide and hydroxycarbamide in combination

\subsection{Treatment Switching}

The frequency and reasons for first treatment switch, since study enrolment, are shown in Table 2. Investigators determined the reason for switching therapy according to their best clinical judgement. Very elderly patients were more likely to be switched from anagrelide than from $\mathrm{HC}$

(a)
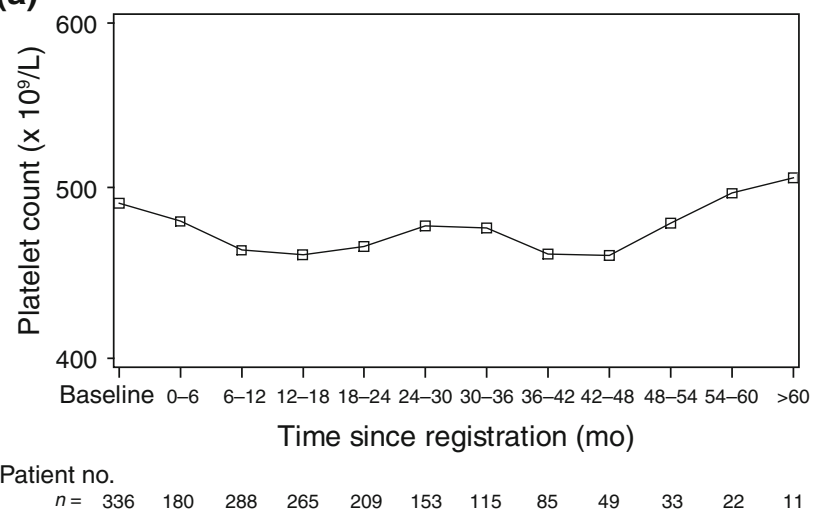

(c)

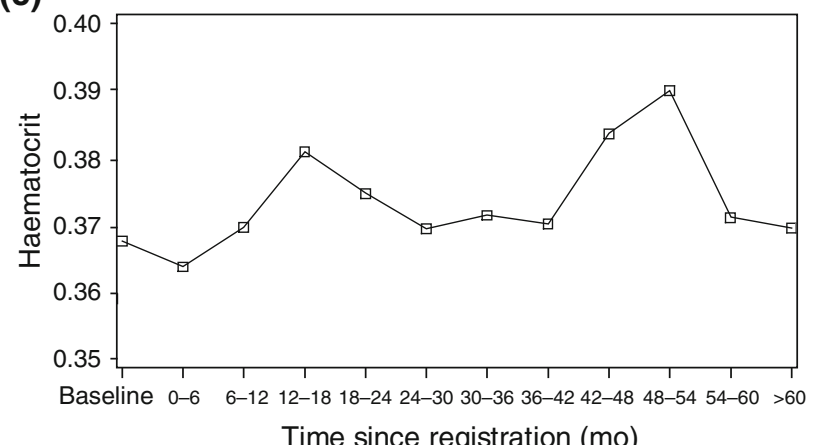

Patient no.

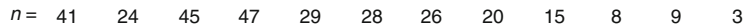

(47.1 vs. $17.4 \%$; $95 \%$ CI for difference in proportion 12.4-46.9; Chi-squared test $p<0.001$ ). The Kaplan-Meier plots illustrate the time to first treatment switch based on survival analysis methodology (Fig. 3). In the total EXELS population, more patients had their therapy switched because of intolerance rather than loss of efficacy ( $28.1 \mathrm{vs.}$ $12.3 \%$; $95 \%$ CI for difference in proportion 12.2-19.3; Chi-squared test $p<0.001$ ). In patients aged $>80$ years, the main reason for switch was intolerance/side effects. However, almost one-third of patients switched for 'other' reasons, which were largely due to lack of control of platelet counts and reductions in counts of white blood cells or $\mathrm{Hb}$ (data not shown). The reasons for first switch were similar between $\mathrm{HC}$ and anagrelide treatment in the overall study population. However, in very elderly patients, $0 / 16$ reported treatment with anagrelide was non-efficacious compared with $8 / 57$ (14\%) patients receiving HC, and $7 / 16(43.8 \%)$ anagrelide patients switched due to intolerance versus 18/57 (31.6\%) patients receiving HC.

\subsection{Predefined Clinical Events}

The total numbers of predefined clinical events (PDEs), and details of notable PDEs, are presented in Table 3. In the

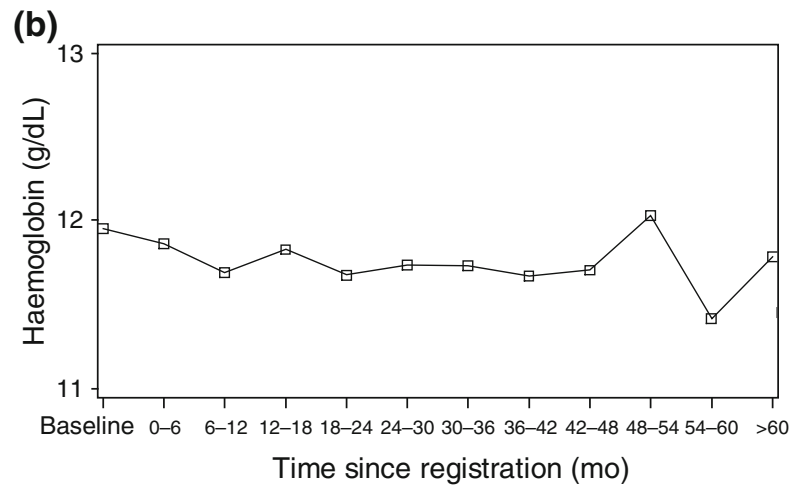

Patient no.

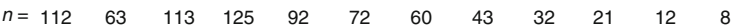

(d)

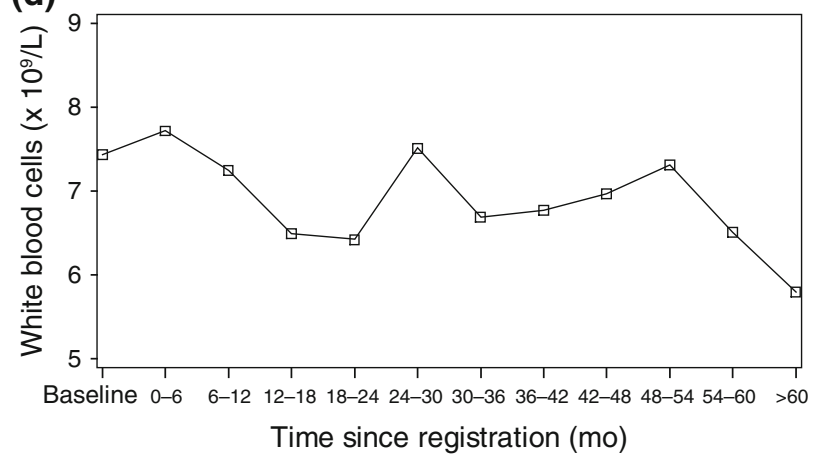

Patient no.

$\begin{array}{llllllllllll}n=91 & 52 & 93 & 84 & 77 & 54 & 44 & 32 & 24 & 14 & 8 & 5\end{array}$

Fig. 2 Evaluation of mean blood cell counts over time in patients aged $>80$ years: (a) platelets, (b) haemoglobin, (c) haematocrit, (d) white blood cells 
Table 2 Treatment switching in patients aged $>80$ years and the total EXELS population

$C I$ confidence interval, $H C$ hydroxycarbamide, $N A$ not applicable

${ }^{a}$ Values are expressed as $\mathrm{n}(\%)$ [95\% CI]

b Patients with missing data: $n=2$

Fig. 3 Kaplan-Meier estimates for first treatment switch in patients aged $>80$ years

\begin{tabular}{|c|c|c|}
\hline \multirow[t]{2}{*}{ Variable } & \multicolumn{2}{|l|}{ Age category ${ }^{a}$} \\
\hline & Age $>80$ years & Total \\
\hline \multicolumn{3}{|l|}{ Frequency of first switch ${ }^{b}$} \\
\hline Switch from any monotherapy & 91/395 (23.0) [18.9-27.2] & $902 / 3,596(25.1)$ \\
\hline Switch from HC monotherapy & $57 / 327(17.4)[13.3-21.5]$ & $455 / 2,340(19.4)$ \\
\hline Switch from anagrelide monotherapy & $16 / 34(47.1)[30.3-63.8]$ & $237 / 792(30.0)$ \\
\hline \multicolumn{3}{|l|}{ Reasons for first switch from $\mathrm{HC}$} \\
\hline Intolerance/side effects & $18 / 57$ (31.6) [19.5-43.6] & $127 / 455(27.9)$ \\
\hline Non-efficacious & $8 / 57(14.0)[5.0-23.1]$ & $55 / 455(12.1)$ \\
\hline Subject preference & $1 / 57(1.8)[0-5.2]$ & $9 / 455(2.0)$ \\
\hline Other & $17 / 57$ (29.8) [17.9-41.7] & $133 / 455(29.2)$ \\
\hline Missing & $10 / 57(17.5)[7.7-27.4]$ & $138 / 455(30.3)$ \\
\hline Unknown & $5 / 57(8.8)[1.4-16.1]$ & $10 / 455(2.2)$ \\
\hline \multicolumn{3}{|l|}{ Reasons for first switch from anagrelide } \\
\hline Intolerance/side effects & $7 / 16(43.8)[19.4-68.1]$ & $69 / 237(29.1)$ \\
\hline Non-efficacious & $0 / 16(0.0)[\mathrm{NA}]$ & $31 / 237(13.1)$ \\
\hline Subject preference & $1 / 16(6.3)[0-18.1]$ & $13 / 237(5.5)$ \\
\hline Other (including economic) & $6 / 16(37.5)[13.8-61.2]$ & $47 / 237(19.8)$ \\
\hline Missing & $2 / 16(12.5)[0-28.7]$ & $76 / 237(32.1)$ \\
\hline Unknown & $0 / 16(0.0)[\mathrm{NA}]$ & 9/237 (3.8) \\
\hline
\end{tabular}

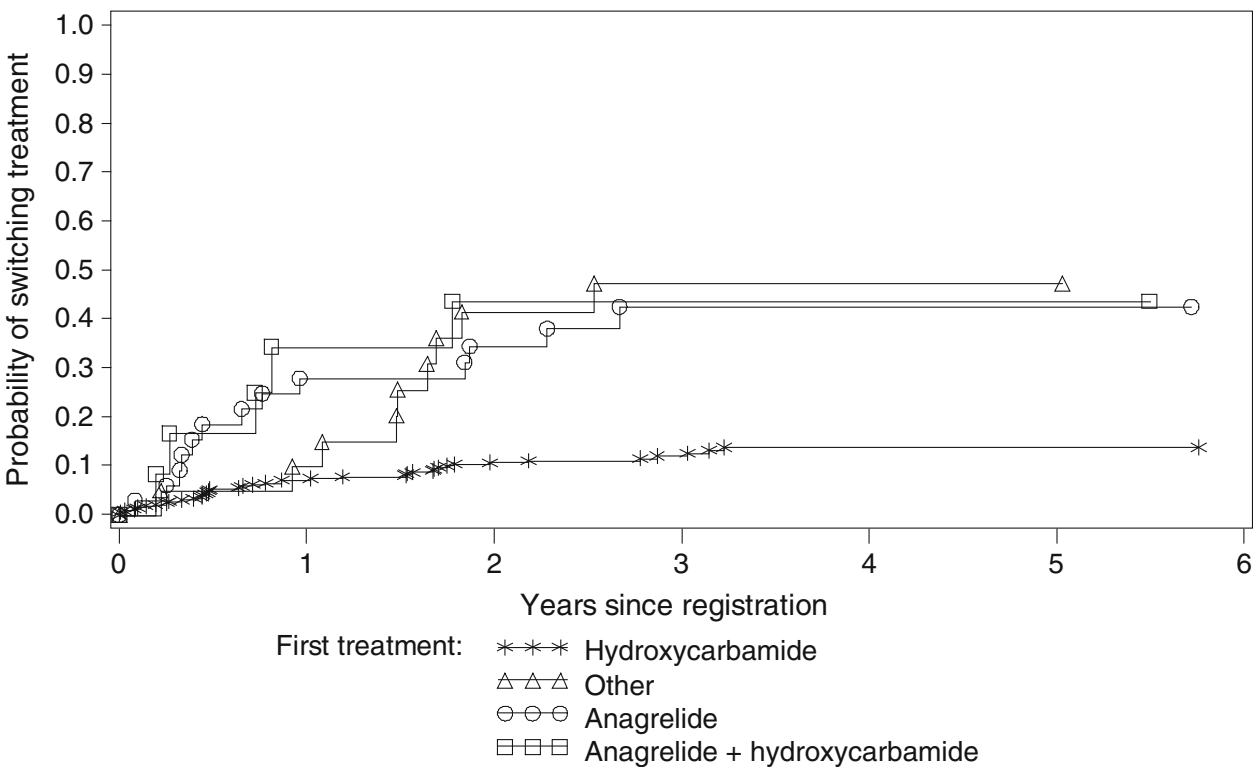

$>80$ years group, $27.3 \%$ of patients experienced at least one PDE. The most common PDEs reported in the very elderly age group were death (non-PDE related; $11.1 \%$ ), other cardiovascular (CV) symptoms (5.8\%), haematological transformation (3.8\%), congestive heart failure (CHF; $3.3 \%)$, and $\mathrm{MI}$ and angina $(2.8 \%)$. There was no association observed between treatment received and occurrence of $\mathrm{CHF}$ or CV symptoms PDEs (data not shown).
The most common type of haematological transformation that occurred in the total EXELS population was myelofibrosis ( $n=49,1.4 \%$ ), followed by acute leukaemia ( $n=37,1.0 \%$ ) and 'other', including transformation to myelodysplasia $(n=27,0.8 \%)$. In patients aged $>80$ years, acute leukaemia $(n=7,1.8 \%)$ and myelofibrosis $(n=4,1.0 \%)$ were also the most frequent transformations. 
Table 3 Numbers of patients with predefined events (PDEs) and numbers of PDEs by age category

\begin{tabular}{|c|c|c|c|c|}
\hline \multirow[t]{3}{*}{ Variable } & \multicolumn{4}{|l|}{ Age category } \\
\hline & \multicolumn{2}{|l|}{ Age $>80$ years $(n=395)$} & \multicolumn{2}{|c|}{ Total $(n=3596)^{\mathrm{a}}$} \\
\hline & $\mathrm{n}(\%)[95 \% \mathrm{CI}]$ & Events & $\mathrm{n}(\%)$ & Events \\
\hline All PDEs reported & $108(27.3)[22.9-31.7]$ & 167 & $636(17.7)$ & 911 \\
\hline \multicolumn{5}{|l|}{ Notable individual PDEs } \\
\hline MI and angina & $11(2.8)[1.2-4.4]$ & 13 & $59(1.6)$ & 66 \\
\hline Stroke & $5(1.3)[0.2-2.4]$ & 6 & $49(1.4)$ & 55 \\
\hline TIA & $4(1.0)[0.0-2.0]$ & 6 & $33(0.9)$ & 38 \\
\hline Intermittent claudication/digital ischaemia & $2(0.5)[0.0-1.2]$ & 2 & $12(0.3)$ & 15 \\
\hline Venous thromboembolic events & $7(1.8)[0.5-3.1]$ & 8 & $44(1.2)$ & 49 \\
\hline Thromboembolic events ${ }^{\mathrm{b}}$ total & $25(6.3)$ [3.9-8.7] & 35 & $186(5.2)$ & 223 \\
\hline Congestive heart failure & $13(3.3)[1.5-5.1]$ & 14 & $35(1.0)$ & 36 \\
\hline Major haemorrhage & $10(2.5)[1.0-4.1]$ & 12 & $58(1.6)$ & 69 \\
\hline Other cardiovascular symptoms & $23(5.8)[3.5-8.1]$ & 29 & $129(3.6)$ & 159 \\
\hline Transformation $^{c}$ & $15(3.8)[1.9-5.7]$ & 15 & $106(2.9)$ & 113 \\
\hline Non-PDE death & 44 (11.1) [8.0-14.2] & 44 & $103(2.9)$ & 103 \\
\hline
\end{tabular}

CI confidence interval, $M I$ myocardial infarction, TIA transient ischaemic attack

${ }^{\text {a }}$ Patients with missing data: $n=2$

b Thromboembolic events defined as: MI and angina, stroke, TIA, intermittent claudication/digital ischaemia, venous thromboembolic events. Note: Some patients experienced more than one thromboembolic event

c Transformation to: acute leukaemia, myelodysplasia, myelofibrosis and 'other'

Thromboembolic events were experienced in $6.3 \%$ $(25 / 395)$ of patients $>80$ years and $5.2 \%(186 / 3,596)$ of the total EXELS cohort (Table 3).

\section{Discussion}

\subsection{Patients}

This prospective observational study of 3,598 patients with ET includes, to our knowledge, the largest population of patients with ET studied to date, including 395 patients aged $>80$ years. Sparse data are available on the treatment of very elderly patients with ET. Notably, Palandri et al. reported data on 118 patients with ET aged $>75$ years, who they classified as very elderly [19]. They retrospectively analysed 326 consecutive patients with ET diagnosed at $>60$ years, although no patients aged $>75$ years received anagrelide and, perhaps because of this, only $5.3 \%$ discontinued HC because of adverse effects. The information collected from EXELS provides valuable insight into the treatment of these very elderly patients in clinical practice.

\subsection{Treatment}

The vast majority of very elderly patients were receiving $\mathrm{HC}$ and although anagrelide was the next most frequently used agent, the proportion of patients receiving it was low
$(8.6 \%)$. These results suggest that the expert recommendations for ET therapy are applied by physicians across Europe [8].

The proportion of patients who were receiving their first cytoreductive treatment, at the time of entering the EXELS study, increased with patient age. The high proportion of very elderly patients receiving first-line $\mathrm{HC}$ is probably due to the fact that there is broad agreement among physicians that $\mathrm{HC}$ is the treatment of choice for very elderly patients and because $\mathrm{HC}$ is well tolerated in general. Concerns regarding the potential leukaemogenicity of $\mathrm{HC}$ are less relevant for older patients than younger ones, since their life expectancy is reduced. Furthermore, physicians may be reluctant to use anagrelide in older patients due to the recognized inotropic effects [9], making $\mathrm{HC}$ the agent of choice and options for switch limited. However, our results have shown that anagrelide can be effective and well tolerated, and provides a good alternative treatment option to busulphan, in very elderly patients for whom $\mathrm{HC}$ is unsuitable. Indeed, Italian guidelines recommend the continuation of anagrelide in patients aged $>60$ years for as long as it continues to be effective [26].

\subsection{Blood Cell Counts}

The initial reduction in platelet counts that was observed in all age groups was shown to be significantly affected by the treatment-naïve population. When these patients were 
removed from the analysis, the platelet counts remained fairly consistent.

The data suggest that the 'target platelet count', the point at which platelet counts are allowed to bottom-out, is $\sim 450 \times 10^{9} / \mathrm{L}$ for the very elderly patients in clinical practice. The criteria for a complete haematological response with ET therapy published by the European LeukemiaNet (ELN) include a target platelet count below $400 \times 10^{9} / \mathrm{L}$ [8]. It is a positive finding that these very elderly patients achieved levels that were close to target. Physicians may be particularly stringent about achieving low platelet counts in very elderly patients as this population has a higher incidence of previous vascular events (also shown in this study), which is a major risk factor for recurrent thrombosis. The ELN guidelines also include the following criteria in the definition of complete haematological response: normal spleen size on imaging, white blood cell count below $10 \times 10^{9} / \mathrm{L}$, and absence of diseaserelated symptoms [8]. However, since EXELS predates the publication of these guidelines, these criteria were not considered in the study design and these data were not collected. Response rates were judged only on platelet levels.

Although anaemia has been reported with both of the major therapeutic agents used in the treatment of myeloproliferative neoplasms, the $\mathrm{Hb}$ values did not change over time in these patients. Anaemia is defined as a $\mathrm{Hb}$ value of $<12 \mathrm{~g} / \mathrm{dL}$ in adult females and $<13 \mathrm{~g} / \mathrm{dL}$ in adult males [21]. The mean baseline $\mathrm{Hb}$ levels in the very elderly population were $12.0 \mathrm{~g} / \mathrm{dL}$, with the median values ranging from 11.5 to $12.3 \mathrm{~g} / \mathrm{dL}$ over time. Since more than two-thirds of these patients were female, the $\mathrm{Hb}$ levels were on the low side of the normal range, which may be due to the large proportion of patients receiving treatment with $\mathrm{HC}$ [22-25].

\subsection{Treatment Switching}

The proportion of very elderly patients switching from anagrelide was 47.1 vs. $17.4 \%$ from $\mathrm{HC}$. The reason for first switch from $\mathrm{HC}$ or anagrelide was more often because of intolerance than loss of efficacy. Similar proportions of patients switched from $\mathrm{HC}$ because of lack of efficacy in our study and that of Palandri et al [19]. Elderly patients have more frequent cardiac abnormalities than younger patients, which may make them more prone to switch treatment if they experience tachycardia or palpitations while receiving anagrelide. A further explanation for high levels of switching from anagrelide in older patients may be that various national guidelines suggest that HC, pipobroman or busulphan are preferable for the treatment of the oldest patients with ET $[8,26]$. However, the small number of very elderly patients treated with anagrelide in EXELS $(n=34)$ precludes the formation of any strong conclusions concerning treatment switching. Low rates of switching therapy because of inefficacy (Table 2), along with almost normal target platelet count observed in patients $>80$ years, show that cytoreductive therapy in very elderly patients is effective. Indeed, tolerance is the main issue in managing patients of all ages with ET in clinical practice and is a particular concern in very elderly patients.

\subsection{Predefined Clinical Events}

Overall, 108 patients aged $>80$ years experienced a total of 167 PDEs, including vascular complications $(n=90)$, haematological transformation (to acute leukaemia or myelofibrosis; $n=15)$ and non-PDE deaths $(n=44)$. However, no new safety concerns were observed in these patients. Thromboembolic events happen in patients with ET, irrespective of the use of cytoreductive therapy, and elderly patients are also recognized to have a slightly increased risk [18]. The very elderly patients in the study by Palandri et al. also experienced a greater thrombotic risk than those aged $<75$ years. [19] Although data on the incidence of angina in a non-MPN population are available [27], uncertainties concerning diagnostic definitions and data collection principles make comparisons with the EXELS population unreliable.

The incidence of stroke and TIA in the very elderly patients in the EXELS study was 1.3 and $1.0 \%$, respectively. In comparison, across Europe between 2001 and 2009, stroke and TIA accounted for $0.45 \%$ of annual hospital admissions in adults aged $\geq 80$ years $(0.29$ and $0.15 \%$ each, respectively) [27]. Therefore, these events were substantially more frequent in the very elderly population in EXELS than the European elderly population. Diseases of the circulatory system (not including angina, MI, ischaemic or pulmonary heart disease, cardiac arrhythmias, cerebrovascular diseases, atherosclerosis or varicose veins), which included pulmonary embolism and deep vein thrombosis, occurred in less than $0.3 \%$ of European adults aged $\geq 80$ years annually between 2001 and 2009 [27]. In comparison, venous thromboembolisms occurred in $1.2 \%$ of all patients in EXELS and $1.8 \%$ of those aged $>80$ years. Therefore, the risk of thromboembolisms was substantially raised in patients in EXELS and particularly so in those aged $>80$ years versus the overall European population.

Of note, similar proportions of patients aged $>80$ years and patients in the overall EXELS population experienced thromboembolic events.

\section{Conclusion}

In conclusion, here we describe an analysis of very elderly patients from the largest ever observational study of 
patients with ET, providing new data on ET management of these patients in clinical practice. The haematological response and normalization of platelet counts achieved with cautious management of these patients is particularly promising. It is also of interest to note that intolerance to cytoreductive therapy is the main reason for treatment switch, not only in these very elderly patients but in patients of all ages.

To summarize, well-tolerated and effective cytoreductive therapy has been achieved in patients aged $>80$ years by following individual treatment modalities that appear in agreement with the recent ELN guidelines. These findings will be confirmed once the study is completed in June 2014.

Acknowledgments The authors acknowledge the contribution of all investigators who participated in this study (see below). JJK has received honoraria from Shire and Novartis for speaking and consulting, support for travel to meetings for manuscript preparation, support from Shire in the form of writing assistance for the manuscript, fees from Shire for participating in steering committee meetings, and research grants from Novartis and Celgene; CB has received fees for educational lectures for Novartis and Shire; MG has no conflicts of interest to declare; LG has received fees from Shire for speaking, travelling to and participating in steering committee meetings; $\mathrm{CH}$ has received research grants, consulting fees/honoraria and payments for speaking from Shire; GB has received an unrestricted research grant from Shire and other payments from Shire for speaking, consulting and travelling to steering committee meetings. $\mathrm{RC}$ is an employee of Shire and holds Shire stocks, and JS is a statistical consultant on a 12-month contract with Shire. The study, funded by the Sponsor, Shire Pharmaceutical Development Ltd, was agreed with the European agency as a post-approval commitment and overseen by the international EXELS steering committee (JJK, CB, $\mathrm{MG}, \mathrm{LG}, \mathrm{CH}$ ), chaired by GB. Under the direction of the authors, Emma Burke and Kerry Acheson, employees of iMed Comms, provided writing assistance for this publication. Editorial assistance in formatting, proofreading, copy editing and fact checking was also provided by iMed Comms. Shire AG reviewed and edited the manuscript for scientific accuracy and provided funding to iMed Comms for support in writing and editing this manuscript. Although the Sponsor was involved in the design, collection, analysis, interpretation and fact checking of information, the content of this manuscript, the ultimate interpretation and the decision to submit it for publication in Clinical Drug Investigation was made by the authors independently.

Investigators who participated in the study Denmark: Ole Weis Bjerrum, Hans Hasselbalch, Carsten Helleberg, Herdis Larsen, Torben Mourits-Andersen, Dorthe Ronnov-Jessen, Hanne Vestergaard; Finland: Eeva Juvonen, Marita Nurmi, Karri Penttila; France: JeanFrancois Abgrall, Sylvia Bellucci, Dominique Bordessoulle, JeanYves Cahn, Natalie Cambier, Nicole Casadevall, Driss Chaoui, Sylvain Choquet, Brigitte Dupriez, Mustapha Kamel Ghomari, JeanJacques Kiladjian, Laurence Legros, Michel Leporrier, Gerard Sebahoun, Michel Tulliez, Jean Francois Viallard, Eric Wattel; Germany: Annette Bittrich, Martin Griesshammer, Bernhard Heinrich, Erhard Hiller, Georg Jacobs, Hendrik Kroening, Axel Matzdorff, Andreas Mohr, Friedrich Overkamp, Yolanda Rodemer, Burkardt Schmidt, Stephen Schmitz, Frank Stegelmann, Hans Tesch, Wolfgang Weber, Juergen Wehmeyer, Johann Weiss, Manfred Welslau, Wolfgang Zeller; Greece: Evangelos Briasoulis, Vasileia Garypidou, Anna Kioumi, Despoina Kyriakou, Eudokia Mandala, Panayiotis Panayiotidis, Helen Papadakis, Basil Seitanidis, Argris Symeonidis, Elina
Vervessou, Michalis Vougarelis, Panayiotis Zikos; Ireland: Gerard Crotty; Italy: Alessandro Andriani, Marino Brunori, Emma Cacciola, Silvana Capalbo, Vincenzo Capparella, Luigi Cavanna, Mario Cazzola, Riccardo Centurioni, Felicetto Ferrara, Gianluca Gaidano, Giovanni Garozzo, Riccardo Ghio, Marco Gobbi, Luigi Gugliotta, Eraldo Lanzi, Anna Marina Liberati, Marcellina Mangoni, Guglielmo Mariani, Massimo Martelli, Vincenzo Martinelli, Maria Gabriella Mazzucconi, Vincenzo Mettivier, Pellegrino Musto, Ubaldo Occhini, Alessandro Polacco, Giovanni Quarta, Maria Luigia Randi, Umberto Recine, Giuseppe Rossi, Stefano Sacchi, Giuseppe Saglio, Potito Rosario Scalzulli, Giorgina Specchia, Valerio de Stefano, Alessia Tieghi, Alessandro M Vannucchi, Giuseppe Visani, Alfonso Zaccaria; Norway: Waleed Ghanima, Marit Rinde, Tove Skjelbakken; Portugal: Pureza Pinto; Spain: Alberto Álvarez-Larrán, José Luis Bello, Carlos Besses, Juan Carlos Hernandez-Boluda, Felix Carbonell, Jesus Cesar, Cristalina Fernandez, Jose Julio Hernandez, Luis HernandezNieto, Esperanza Lavilla, Javier Loscertales, Francisca Ferrer Marin, Jose R Mayans, Jesus M Hernandez Rivas, Francisco J de la Serna, Ana Villegas, Blanca Xicoy; Sweden: Jesper Aagesen, Tomas Ahlgren, Gunnar Birgegard, Honar Dylman, Peter Johansson, Olle Linder, Eva Lofvenberg, Jan Samuelsson, Kristina Wallman; The Netherlands: S Zweegman; UK: Sara Ali, Nigel O Connor, Roger Evely, Savio Fernandes, Claire Harrison, Mary F McMullen, Don Milligan, Beverley Paul, Shalal Sadullah, Charles Singer, Chris Tiplady, Peter Williamson.

Open Access This article is distributed under the terms of the Creative Commons Attribution Noncommercial License which permits any noncommercial use, distribution, and reproduction in any medium, provided the original author(s) and the source are credited.

\section{References}

1. Swerdlow SH, Campo E, Harris NL, et al. WHO Classification of Tumours of Haemopoietic and Lymphoid Tissues. 4th ed. Lyon: IARC Press; 2008

2. Johansson P. Epidemiology of the myeloproliferative disorders polycythemia vera and essential thrombocythemia. Semin Thromb Hemost. 2006;32:171-3.

3. Ma X, Vanasse G, Cartmel B, et al. Prevalence of polycythemia vera and essential thrombocythemia. Am J Hematol. 2008;83: 359-62.

4. Besses C, Cervantes F, Pereira A, et al. Major vascular complications in essential thrombocythemia: a study of the predictive factors in a series of 148 patients. Leukemia. 1999;13:150-4.

5. Cortelazzo S, Viero P, Finazzi G, et al. Incidence and risk factors for thrombotic complications in a historical cohort of 100 patients with essential thrombocythemia. J Clin Oncol. 1990;8:556-62.

6. Cortelazzo S, Finazzi G, Ruggeri M, et al. Hydroxyurea for patients with essential thrombocythemia and a high risk of thrombosis. N Engl J Med. 1995;332:1132-6.

7. Passamonti F, Rumi E, Pungolino E, et al. Life expectancy and prognostic factors for survival in patients with polycythemia vera and essential thrombocythemia. Am J Med. 2004;117:755-61.

8. Barbui T, Barosi G, Birgegard G, et al. Philadelphia-negative classical myeloproliferative neoplasms: critical concepts and management recommendations from European LeukemiaNet. J Clin Oncol. 2011;29:761-70.

9. European Medicines Agency. Summary of Product Characteristics. http://www.ema.europa.eu/docs/en_GB/document_library/ EPAR_-_Product_Information/human/000480/WC500056557.pdf. Accessed 7 Feb 2012. 
10. Anagrelide Study Group. Anagrelide, a therapy for thrombocythemic states: experience in 577 patients. Am J Med. 1992;92:69-76.

11. Birgegard G, Bjorkholm M, Kutti J, et al. Adverse effects and benefits of two years of anagrelide treatment for thrombocythemia in chronic myeloproliferative disorders. Haematologica. 2004;89:520-7.

12. Gugliotta L, Tieghi A, Tortorella G, et al. Low impact of cardiovascular adverse events on anagrelide treatment discontinuation in a cohort of 232 patients with essential thrombocythemia. Leuk Res. 2011;35:1557-63.

13. Harrison CN, Campbell PJ, Buck G, et al. Hydroxyurea compared with anagrelide in high-risk essential thrombocythemia. N Engl J Med. 2005;353:33-45.

14. Kiladjian JJ, Besses C, Griesshammer M, et al. Management of elderly patients with essential thrombocythemia: an observational study of 471 patients of 80 years and older included in the EXELS European study [abstract no. 0911]. Haematologica 2011;96(Suppl. 2):379.

15. Lackner H, Urban C, Beham-Schmid C, et al. Treatment of children with anagrelide for thrombocythemia. J Pediatr Hematol Oncol. 1998;20:469-73.

16. Mazzucconi MG, Redi R, Bernasconi S, et al. A long-term study of young patients with essential thrombocythemia treated with anagrelide. Haematologica. 2004;89:1306-13.

17. Mitura-Lesiuk M, Filiks-Litwin B, Malek U, et al. Diagnostic and therapeutic management of essential thrombocythemia in children [in Polish]. Med Wieku Rozwoj. 2004;8:834-8.

18. Engbers MJ, van Hylckama Vlieg A, Rosendaal FR. Venous thrombosis in the elderly: incidence, risk factors and risk groups. J Thromb Haemost. 2010;8:2105-12.
19. Palandri F, Polverelli N, Catani L, et al. Very elderly patients with essential thrombocythaemia: are they a separate category? A monocentric study on 118 patients older than 75 years. Br J Haematol. 2012;156:676-9.

20. Murphy S, Peterson P, Iland H, et al. Experience of the Polycythemia Vera Study Group with essential thrombocythemia: a final report on diagnostic criteria, survival, and leukemic transition by treatment. Semin Hematol. 1997;34:29-39.

21. World Health Organization. Worldwide prevalence of anaemia 1993-2005. Geneva: WHO; 2008.

22. Jabr FI, Shamseddine A, Taher A. Hydroxyurea-induced hemolytic anemia in a patient with essential thrombocythemia. Am J Hematol. 2004;77:374-6.

23. Martinez-Trillos A, Gaya A, Maffioli M, et al. Efficacy and tolerability of hydroxyurea in the treatment of the hyperproliferative manifestations of myelofibrosis: results in 40 patients. Ann Hematol. 2010;89:1233-7.

24. Patel KV. Variability and heritability of hemoglobin concentration: an opportunity to improve understanding of anemia in older adults. Haematologica. 2008;93:1281-3.

25. Penninga E, Jensen BA, Hansen PB, et al. Anagrelide treatment in 52 patients with chronic myeloproliferative diseases. Clin Lab Haematol. 2004;26:335-40.

26. Barbui T, Barosi G, Grossi A, et al. Practice guidelines for the therapy of essential thrombocythemia. A statement from the Italian Society of Hematology, the Italian Society of Experimental Hematology and the Italian Group for Bone Marrow Transplantation. Haematologica. 2004;89:215-32.

27. European Commission. EUROSTAT. http://epp.eurostat.ec. europa.eu/portal/page/portal/health/public_health/data_public_ health/database. Accessed 2 July 2012. 